\title{
Exactitud del ELISA para el diagnóstico de fascioliasis bovina: análisis del área bajo la curva del receptor operador (ROC)
}

\author{
Luis C. Orozco ${ }^{1}$, Clemencia E. Ovalle², Sofía Duque ${ }^{3}$, Myriam C. López $^{3}$, Rubén S. Nicholls ${ }^{3}$
}

\section{Resumen}

Se estandarizó y evaluó la prueba de ELISA para el serodiagnóstico de la fascioliasis bovina empleando tres antígenos diferentes de Fasciola hepatica: somático crudo (AgS) y metabólicos, excretor-secretor total (AgE/S-T) y excretor-secretor parcialmente purificado (AgE/S-PP).

Se recolectaron treinta muestras de suero de bovinos infectados naturalmente con $F$. hepatica y parasitológicamente comprobados, sacrificados en mataderos. Estos provenían de regiones de Colombia consideradas zonas endémicas, que se encuentran por encima de los 1.800 metros msnm, y 45 sueros de bovinos de edad y manutención conocida desde el nacimiento hasta su sangría, los cuales vivían en zona no endémica de $F$. hepatica y que fueron consideradas como muestras negativas.

Se utilizó el análisis dẹl área bajo la curva del receptor operador $(\mathrm{ROC})$ siguiendo el método de integración trapezoidal para establecer la exacitud del ELISA y discriminar ejemplares parasitados de los sanos. Los tres antígenos de F. hepatica, (AgS) , (AgE/ $\mathrm{S}-\mathrm{T})$ y (AgE/S PP), debido a su gran capacidad discriminatoria entre bovinos sanos de los infectados, pueden utilizarse en el serodiagnóstico de fascioliasis bovina.

\section{Summary}

The enzyme-linked immuno-sorbent assay (ELISA) test for the serodiagnosis of bovine fascioliasis was standardized and evaluated.

Three kinds of antigen were employed: crude somatic (SAg), total excretory/secretory (T-E/SAg) and partially purified excretory/secretory (PP-E/SAg).

Thirty positive samples were obtained from naturally infected cattle, parasitological confirmation being positive due to the finding of adult flukes in bile ducts during post-mortem examination. The infected cattle came from regions lying between 1,800 and 2,400 meters above sea level, which are considered to be endemic for this disease.

Forty-five negative samples were obtained from cattle living in non-endemic areas, whose age, breeding and growth conditions had been recorded since birth to the actual moment at which the blood samples were taken.

The receiver operator curve (ROC) was used for the evaluation of the ELISA test, following trapezoidal integration methodology, in order to identify parasitized bovines from

1 Laboratorio de Patología, Instituto Nacional de Salud, Santa Fe de Bogotá, D.C., Colombia.
2 Facultad de Ciencias, Pontificia Universidad Javeriana, Santa Fe de Bogotá, D.C., Colombia.
3 Laboratorio de Parasitología, Instituto Nacional de Salud. Santa Fe de Bogotá,D.C., Colombia. 
healthy ones. The three antigens employed -somatic (SAg), total excretory/secretory (T-E/SAg) and partially purified excretory/secretory (PP-E/SAg)- can be used for performing fascioliasis serodiagnosis by ELISA test because all of them differentiate positive from negative samples.

La fascioliasis es una parasitosis ampliamente distribuida en el mundo. Su frecuencia varía de una región a otra, de un hato a otro y entre los animales de un mismo rebaño según la edad (1). La enfermedad es un proceso crónico que produce tanto trastornos digestivos como de la nutrición, causado por la acción del tremátodo Fasciola hepatica sobre el parénquima y conductos biliares de bovinos, ovinos, caprinos, algunos animales silvestres y el hombre (1).

F. hepatica es el tremátodo más importante y nocivo de los bovinos, constituyéndose en un endoparásito que ocasiona grandes pérdidas económicas debidas al retardo en el crecimiento de los bovinos jóvenes infectados, al decomiso en los mataderos de hígados de los animales parasitados, a los abortos y a la disminución en la producción de leche (2). Los huéspedes intermediarios del tremátodo son caracoles del género Lymnea (3). En las zonas donde existe este parásito, además de que la producción bovina está seriamente afectada, se pueden presentar casos en humanos.

En Colombia, la prevalencia de infección por $F$. hepatica se estima en 20 a $25 \%$ en las ganaderías de leche de clima frío del país, a saber: Cundinamarca, Boyacá, Nariño, parte de Santander y Norte de Santander, y se presenta con menos frecuencia en algunas zonas de Antioquia, el viejo Caldas, Cauca, Valle del Cauca, Tolima, Huila y Meta (4). El diagnóstico de fascioliasis se hace habitualmente mediante la identificación de huevos de Fasciola en materia fecal, que si bien es patognomónico para la presencia del parásito presenta una sensibilidad de $74 \%$, menor que la obtenida al realizar los métodos inmunodiagnósticos que informan un $86 \%$ utilizando el inmunoensayo en capa delgada (ICD) (5). Por ello, el serodiagnóstico de la fascioliasis es una alternativa útil (6). Algunas de las pruebas inmunológicas utilizadas para el serodiagnóstico de fascioliasis son: intradermorreacción (7), fijación de complemento (FC) (8), reacciones de precipitación: doble difusión (DD) (9), contrainmunoelectroforesis (CIE) (10), hemoaglutinación pasiva (11), inmunoensayo en capa delgada (5), inmunofluorescencia (IFI) (12) y prueba inmunoenzimática (ELISA) (13).

El serodiagnóstico de fascioliasis permite demostrar la presencia de anticuerpos utilizando diferentes fuentes de antígeno: somático crudo completo homogenizado o en diferentes grados de purificación del parásito adulto y productos metabólicos; productos de excreción y secreción (E/S) (14). Se conoce que los antígenos metabólicos del parásito juegan un papel importante en el estímulo para formación de anticuerpos y éstos aparecen antes de los hallazgos clínicos y parasitológicos (14).

EI ELISA es un procedimiento inmunodiagnóstico ampliamente utilizado para la detección de anticuerpos o antígenos de agentes infecciosos, entre ellos los parásitos, que pueden causar enfermedad en humanos (15) o en animales (16). Sin embargo, el uso del ELISA para el serodiagnóstico de fascioliasis bovina ha sido objeto de menor atención con respecto a otras metodologías inmunodiagnósticas. Burden y Hammet, en 1978, describieron el ELISA como herramienta inmunodiagnóstica para el serodiagnóstico de fascioliasis bovina (13), pero, en el mismo año, Van Tiggele y Over informaron que las pruebas de hemoaglutinación indirecta $(\mathrm{HI})$, inmunoelectroforesis (ID) y (CIE) utilizando extracto crudo de Fasciola como antígeno, eran más útiles que el ELISA y FC. (17). Ambroise-Thomas y colaboradores, en 1980 , al utilizar antígeno delipidado no encontraron diferencia significativa entre sanos y enfermos (18). Un año después, Farrell y colaboradores, al comparar la detección de la infección por Fasciola mediante el ELISA utilizando cuatro antígenos crudos diferentes: fresco, extraido de fasciolas adultas muertas, liofilizado y 
parcialmente purificado, para el inmunodiagnóstico experimental y natural de fascioliasis bovina, encontraron que el antígeno crudo fresco (esencialmente homogenizado) ofrecía la más alta actividad porque detectaba la infección a las cuatro semanas (19). En 1984, dos grupos de investigadores $(14,20)$ evaluaron la aplicabilidad del ELISA para el inmunodiagnóstico de fascioliasis bovina. Los primeros comunicaron que, aunque la prueba detectaba anticuerpos, los resultados eran inconsistentes, pero proponían la posibilidad de trabajar el ELISA usando antígenos metabólicos para mejorar la sensibilidad (14). Los segundos, al evaluar la prueba en condiciones de campo, informaron que el ELISA era una metodología específica para el inmunodiagnóstico de fascioliasis bovina (20). Un año más tarde, Hillyer y colaboradores, al utilizar como antígeno el tegumento del parásito, debido a que éste es género-específico, encontraron que la ID y el ELISA ofrecían mejores resultados que la CIE (21). En 1986, Wyckoff y Bradley utilizaron antígeno crudo y desarrollaron el ELISA cinético y cuantitativo. Informaron que era de gran utilidad para estudios de tamizaje y de detección de infeccion prepatente (22). Al año siguiente, Welch y colaboradores evaluaron el ELISA como método para determinar la tasa de inmunoconversión relativa en terneros y cómo ésta puede ser correlacionada con la prevalencia de infección determinada mediante la excreción de huevos de $F$. hepatica en materia fecal (23). En 1988, Sinclair y Wassall, utilizando antígeno somático para el ELISA, obtuvieron menor sensibilidad que utilizando antígenos metabólicos (24).

Varios grupos han evaluado los antígenos metabólicos excretores-secretores y preparaciones de éstos parcialmente purificados para su utilización como antígeno en el ELISA. Lehner y Sewell, en 1980, fraccionaron antígeno E/S mediante Sephadex-200 y encontraron actividad antigénica principalmente en las fracciones de mayor peso molecular (25). Dos años después, Irving y Howell demostraron que los polipéptidos de peso molecular de 22, 24 y $26 \mathrm{kDa}$ se producían en medio de cultivo (26). En 1984, Pfister y colaboradores evaluaron antígeno $\mathrm{E} / \mathrm{S}$ observando que tanto moléculas mayores de $10 \mathrm{kDa}$ como aquéllas entre 2-10 kDa presentaban actividad antigénica (14). Zimmerman y colaboradores, en 1986, manifiestaron la existencia de reacción cruzada con componentes de peso molecular entre 81200 kDa (27). Sin embargo, Rivera y colaboradores, en 1988, informaron que la infección temprana de fascioliasis puede detectarse con fracciones de alto peso molecular (150-160 kDa) y la fascioliasis aguda con las de 25-30 kD (28) como lo habían demostrado Santiago y colaboradores (29). La detección de anticuerpos contra $F$. hepatica se ha realizado en varios modelos animales utilizando antígenos E/S (30) y actualmente, 1995, se ha extrapolado su aplicación para el inmunodiagnóstico de fascioliasis en caprinos (31).

La presente investigación realizó la estandarización y la evaluación del inmunoensayo ELISA utilizando tres tipos de antígeno: somático crudo total, excretor/secretor total y excretor/ secretor parcialmente purificado para el inmunodiagnóstico de fascioliasis bovina, siguiendo la metodología propuesta por Nierenberg y Feinstein (32).

\section{Materiales y métodos}

\section{Obtención de Fasciola hepatica}

Se recolectaron adultos de $F$. hepatica de los conductos biliares de hígados de los bovinos infectados naturalmente que se encontraron parasitados en el momento de su sacrificio.

\section{Muestra de suero}

Se recolectaron 30 muestras de sangre para la obtención de suero de bovinos parasitológicamente comprobados, por la presencia de adultos de $F$. hepatica en el hígado, y de 45 bovinos que vivían en zona no endémica de fasciolasis, de edad y manutención conocida desde el nacimiento hasta su sangría lo que permitió confirmar la ausencia de contacto con F. hepatica.

\section{Obtención de antígeno}

\section{Somático}

Los parásitos adultos se lavaron con solución salina fisiológica estéril y se homogenizaron. EI 
material obtenido se congeló a $-196^{\circ} \mathrm{C}$ (nitrógeno líquido) y descongeló a $4^{\circ} \mathrm{C}$ durante tres veces consecutivas. Este se centrifugó a $850 \times \mathrm{g}$ durante 30 minutos a $4^{\circ} \mathrm{C}$. El sobrenadante (antígeno) se recolectó, distribuyó en alícuotas, y almacenó a $-20^{\circ} \mathrm{C}$, previa determinación de su concentración de proteínas por el método de Lowry (33).

\section{Antígeno excretor/secretor total}

Los parásitos adultos se lavaron $3 \circ 4$ veces con solución amortiguadora de fosfatos (PBS), durante 1 hora, a temperatura ambiente. Se incubaron dos adultos por cada alícuota de 5 $\mathrm{mL}$ de PBS, que contenía $100 \mathrm{U}$ penicilina/mL y $100 \mu \mathrm{g}$ de estreptomicina $/ \mathrm{mL}$, a $37^{\circ} \mathrm{C}$, durante 3 horas, tiempo después del cual los adultos se retiraron del PBS. La solución que contenía los parásitos se centrifugó a $4.400 \times g$ durante una hora a $4^{\circ} \mathrm{C}(28,34)$. El sobrenadante (antígeno) se recolectó, distribuyó, en alícuotas y almacenó a $-20^{\circ} \mathrm{C}$, previa determinación de su concentración de proteínas por el método de Lowry.

\section{Antígeno excretor/secretor parcialmente purificado}

Se realizó la misma metodología utilizada para la obtención de AgE/S-T con la diferencia de que, una vez obtenido el sobrenadante (antígeno), éste se dializó frente a PBS utilizando una membrana Spectra/por 1, $M W C O^{\circledR}$, que permite la retención de moléculas de peso molecular mayores de 6-8 kDa, reemplazándolo cada ocho horas, durante 48 horas. El antígeno se concentró a un volumen final cinco veces menor al obtenido, utilizando Ficoll ${ }^{\circledR}$; se recolectó, distribuyó en alícuotas y almacenó a $-20^{\circ} \mathrm{C}(34,35)$, después de determinar su concentración de proteínas por el método de Lowry.

\section{Ensayo inmunoenzimático (ELISA)}

\section{Estandarización}

Se determinaron las concentraciones óptimas de antígeno, suero, conjugado y las condiciones requeridas para el procedimiento (15).

1. Concentración óptima de antígeno: se evaluaron las siguientes concentraciones de antígeno para determinar la concentración óptima de cada uno de ellos: Ag somático crudo de 0,5 a $80 \mu \mathrm{g} / \mathrm{mL}$; Ag excretor/secretor total de 1 a $10 \mu \mathrm{g} / \mathrm{mL}$ y excretor/secretor parcialmente purificado de $0,5-10 \mu \mathrm{g} / \mathrm{mL}$.

2. Dilución óptima del suero: se utilizaron dos sueros de bovinos: uno provenía de un ejemplar parasitado con F. hepatica, suero positivo; y, el otro, de bovino sin antecedentes de contacto anterior con el parásito, suero negativo. Se confrontaron, con cada una de las concentraciones de antígeno anteriormente mencionadas, las siguientes diluciones de suero positivo y negativo para establecer la dilución óptima de la muestra según el antígeno utilizado. Con el antígeno somático se utilizaron diluciones desde 1:25 a 1:1.600; con el antígeno excretor/secretor total y el antígeno excretor/secretor parcialmente purificado diluciones a partir de 1:75 a 1:1.600.

3. Dilución óptima de conjugado: se usaron diferentes diluciones de anti-lgG bovina unida a peroxidasa (Sigma Chemical Co. A-7414) para establecer, según el antígeno utilizado, la dilución óptima de éste. Las diluciones utilizadas con antígeno somático fueron desde 1:1000 a 1:10.000; con el antígeno excretor/secretor total, diluciones entre $1: 4.000$ a $1: 7.000$, y con el antígeno excretor/secretor parcialmente purificado, diluciones a partir de 1:1.000 a 1:10.000.

4. Condiciones de la metodología: se realizó bloqueo de posibles sitios activos en la microplaca con gelatina en concentraciones desde 0,1 a $3 \%$.

\section{Procedimiento}

1. Se llevó a cabo la metodología del ELISA descrita por Voller y colaboradores en 1976 (15).

Se colocaron $100 \mu \mathrm{L}$ de cada una de las diferentes concentraciones de AgS o AgE/S-T o $\mathrm{AgE} / \mathrm{S}-\mathrm{PP}$, disueltas en solución amortiguadora de carbonato $0,9 \mathrm{M}, \mathrm{pH} 9,6$, por triplicado, en los pozos de la microplaca y se incubaron a temperatura ambiente durante tres horas en cámara húmeda. Se lavó la microplaca tres veces consecutivas con PBS-tween, cada vez 
durante cinco minutos. Se agregaron $100 \mu \mathrm{L}$ de cada una de las diluciones de los sueros, realizadas en PBS-tween, por triplicado, en la microplaca e incubaron a temperatura ambiente durante dos horas en cámara húmeda. La microplaca se lavó como se mencionó anteriormente. Posteriormente, se agregaron 100 $\mu \mathrm{L}$ de cada una de las diluciones de conjugado, disueltas en PBS-tween, por triplicado, en la microplaca e incubaron a $4^{\circ} \mathrm{C}$ durante 18 horas. Se realizó un lavado igual a los anteriores. Finalmente, se agregaron $100 \mu \mathrm{L}$ de solución sustrato ortofenil-endiamina (OPD) y se incubó la microplaca a temperatura ambiente, protegiéndola de la incidencia de la luz, durante 30 minutos. La reacción enzima-sustrato se detuvo con $25 \mu \mathrm{L}$ de ácido sulfúrico $0,1 \mathrm{~N}$ y la absorbancia se determinó a una longitud de onda de $492 \mathrm{~nm}$ en un colorímetro Uniskan I.

2. ELISA con bloqueo de posibles sitios activos en la microplaca: se realizó la misma metodología del ELISA descrito por Voller y colaboradores en 1976 (15), pero introduciendo el bloqueo de posibles sitios activos de la microplaca mencionado anteriormente antes de adicionar las muestras de suero.

3. ELISA con bloqueo para posibles moléculas semejantes al antígeno: se realizó la misma metodología del ELISA descrito por Voller y colaboradores en 1976 (15), pero introduciendo el bloqueo para eliminar reacción inespecífica antes de agregar las diluciones de conjugado.

Se llevó a cabo el ELISA con los diferentes bloqueos planteados con la finalidad de eliminar cualquier posible factor que pudiese interferir con la prueba.

\section{Evaluación}

Se evaluó el ELISA con sueros de 30 bovinos, parasitológicamente comprobados por la presencia de adultos de $F$. hepatica en el hígado y 45 que vivían en zona no endémica de fascioliasis en Colombia, donde nunca se ha demostrado la presencia del parásito.

\section{Análisis}

Estandarización: las diluciones óptimas de cada uno de los antígenos procesados y las de suero y conjugado, para utilizar con cada uno de los antígenos valorados, se determinaron estableciendo el valor de absorbancia que permitió diferenciar claramente una muestra positiva de una negativa (15).

Exactitud de la prueba: para establecer la exactitud de la prueba en separar ejemplares parasitados de los sanos, se utilizó el análisis del área bajo la curva del receptor operador (ROC) (36) siguiendo el método de integración trapezoidal con lo cual se obtiene el área bajo la curva y el error estándar de la misma.

\section{Resultados}

\section{Antígenos}

Las concentraciones de proteína obtenidas para los antígenos somático-crudo, excretor/secretor total y excretor/secretor parcialmente purificado de $F$. hepatica fueron $7,1,3$ y $2,8 \mathrm{mg} / \mathrm{mL}$, respectivamente.

\section{Ensayo inmunoenzimático (ELISA)}

\section{Estandarización}

1. Concentración óptima de antígeno: las concentraciones óptimas de los diferentes antígenos fueron: antígeno somático crudo: 7,5 $\mu \mathrm{g} / \mathrm{mL}$; antígeno excretor-secretor total: $7.5 \mu \mathrm{g} /$ $\mathrm{mL}$; y antígeno excretor-secretor parcialmente purificado: $0,75 \mu \mathrm{g} / \mathrm{mL}$.

2. Dilución óptima de suero: las diluciones óptimas de suero fueron: 1:800, 1:125 y 1:100 utilizando antígeno somático, antígeno excretorsecretor total y antígeno excretor-secretor parcialmente purificado, respectivamente.

3. Dilución óptima de conjugado: las diluciones óptimas de conjugado fueron: 1:6.000, 1:7.000 y 1:2.000, utilizando antígeno somático, antígeno excretor-secretor total y antígeno excretor-secretor parcialmente purificado, respectivamente.

4.Metodología del ELISA: los bloqueos no cambiaron los valores de absorbancia obtenidos con el procedimiento del ELISA sin bloqueo o ELISA estándar. El valor promedio de las absorbancias obtenidas a $492 \mathrm{~nm}$ al procesar el suero positivo y el negativo mediante ELISA estándar y con bloqueo fue respectivamente de 
0,499 (DE: 0,036) y 0,476 (DE: 0,005) para la muestra positiva y de 0,261 (DE: 0,0007) y 0,290 (DE: 0127) con el suero negativo.

\section{Evaluación}

Análisis ROC: las áreas bajo la curva para cada uno de los antígenos, AgS, AgE/S-T y AgE/ SPP, se presentan en el cuadro 1 y las curvas ROC se observan en la figura 1.
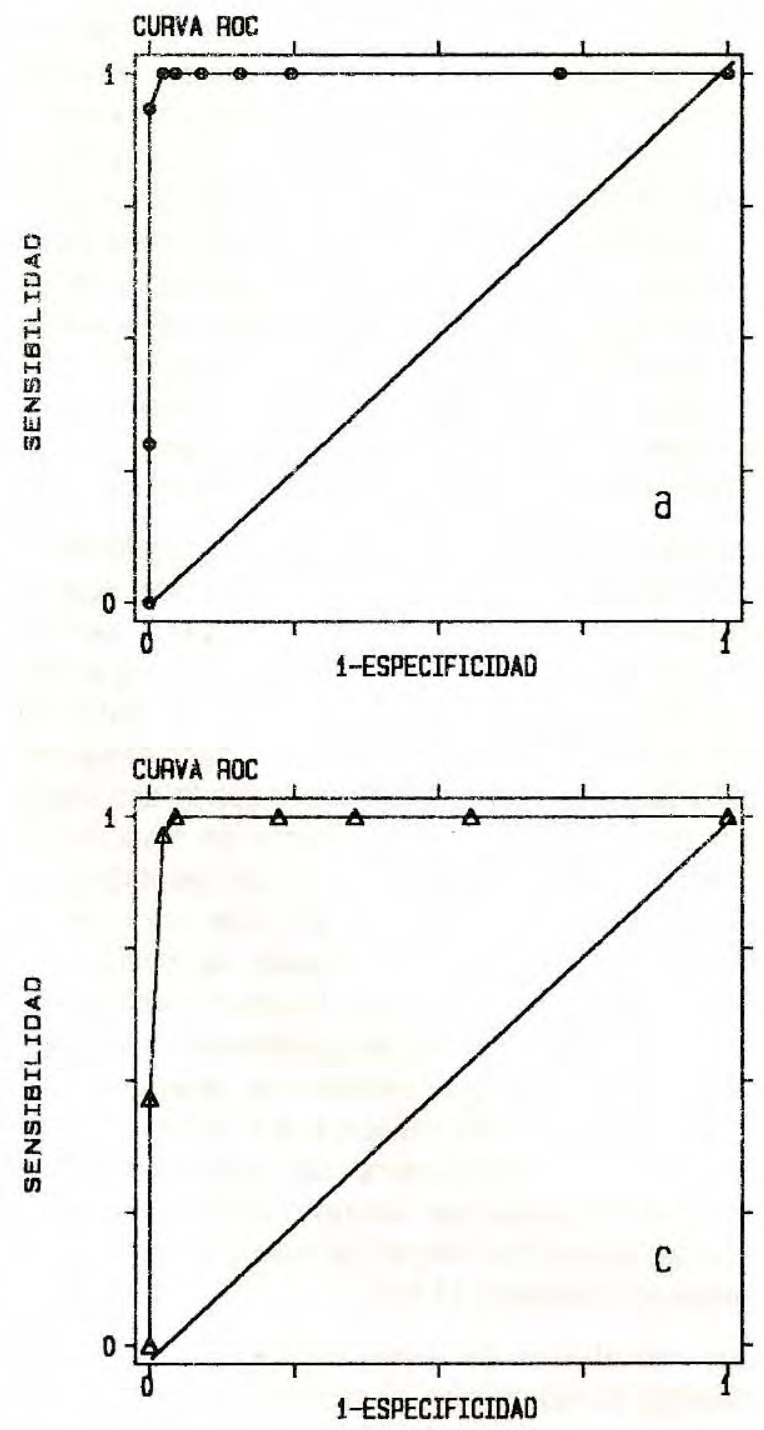

Cuadro 1. Areas bajo la curva del receptor operador (ROC)

para los tres antígenos.

\begin{tabular}{lcc}
\hline Antígeno & Area & IC 95\% \\
\hline Somático & 0,993 & $0,979-1,0$ \\
Excretor/secretor total & 0,996 & $0,988-1,0$ \\
Excretor/secretor & 1,0 & --- \\
parcialmente purificado & 1,0 & \\
\hline
\end{tabular}

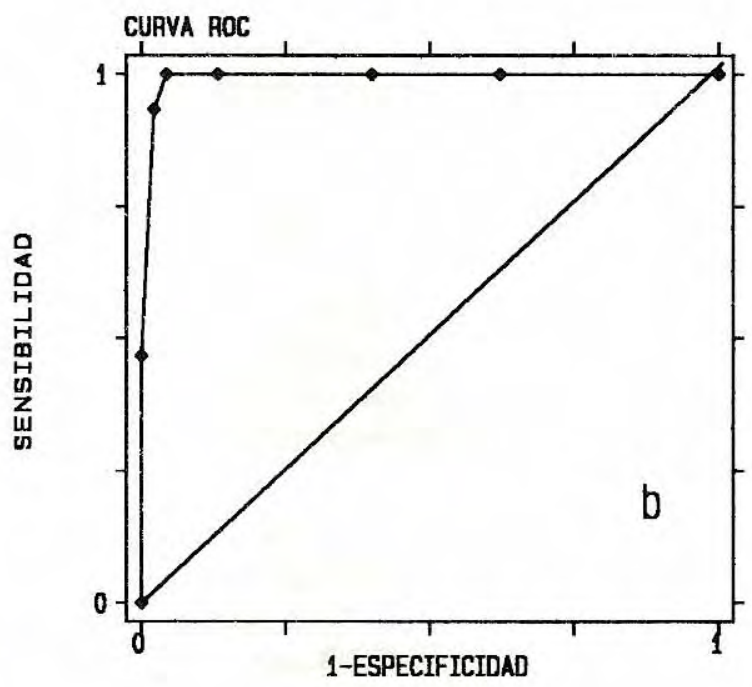

Figura 1. Areas bajo la curva del receptor operador (ROC) para los tres antígenos

a. Antígeno somático, b. Antígeno excretor/secretor total, c. Antígeno excretor/secreto parcialmente purificado. 


\section{Discusión}

A pesar de la larguísima tradición de estandarizar y evaluar pruebas diagnósticas, aún se cometen muchos errores en su análisis. Uno muy frecuente es que no se tienen en cuenta las diferentes fases que deben realizarse en el proceso de establecer una metodología como prueba diagnóstica (32). Otro es que, tradicionalmente, la exactitud de una prueba diagnóstica se basa en el análisis de la sensibilidad y la especificidad. Sin embargo, para tal efecto en el caso de una variable continua como lo es la absorbancia, es necesario establecer un punto de corte que arbitrariamente se ha definido como el valor del promedio más dos desviaciones estándar de las muestras negativas (37).

Estos dos procedimientos habituales no tienen en cuenta que, en la fase inicial de la estandarización de una prueba diagnóstica, se busca un máxima capacidad discriminatoria que en el caso de una variable continua tendrá muy diferentes valores dependiendo del punto de corte escogido.

Esto representa para una prueba como ELISA una pérdida de información del análisis de una variable que es continua. Para este tipo de variables, la metodología ROC aprovecha toda la información disponible. En estas condiciones el área bajo la curva (ROC) es mucho más informativa porque utiliza toda la información disponible y adicionalmente incluye toda las posibles sensibilidades y especificidades.

La recomendación habitual de la escogencia del punto de corte (37) como la media más dos desviaciones estándar de las muestras negativas, asume una distribución normal de las mismas lo cual no siempre es verdadero (24).

Es evidente por los valores de las tres áreas bajo la curva ROC para cada uno de los antígenos utilizados, que el poder discriminatorio de la prueba ELISA del estudio es casi perfecto, lo cual es de esperarse debido a la naturaleza de las poblaciones analizadas. Además, puede concluirse que el tipo de antígeno no afecta el poder discriminatorio de la prueba.
La utilización del ELISA como prueba inmunodiagnóstica de fascioliasis bovina ha sido controvertida desde 1978 cuando Burden y Hammet la desarrollaron con tal fin (13). Su cuestionamiento se ha basado en la variación del poder discriminatorio del inmunoensayo, el cual, según algunos autores, es consecuencia del tipo de antígeno de F. hepatica utilizado para la ejecución de la prueba. Así, según Van Tiggele y Over, el antígeno crudo somático utilizado en el ELISA no es tan útil como si lo es para las pruebas HI, ID, CIE (17). Sin embargo, Farrell y colaboradores al comparar la eficacia del ELISA utilizando cuatro antígenos crudos diferentes -somático crudo fresco, somático extraído de fasciolas muertas, liofilizado y parcialmente purificadodemostraron que el antígeno somático crudo homogenizado ofrecía la más alta actividad para detectar la infección a las cuatro semanas tanto en bovinos infectados experimentalmente como en aquéllos infectados naturalmente (19). El ELISA del presente estudio demuestra que el antígeno somático crudo permite discriminar claramente bovinos sanos de los infectados .

Sinclair y Wassall, utilizando la doble difusión como prueba de referencia, encontraron que el ELISA con antígeno somático detecta menos muestras positivas que los antígenos metabólicos (24). La utilización de éstos y preparaciones de los mismos, parcialmente purificados $(25,26)$ demuestra que la actividad antigénica radica principalmente en fracciones de mayor peso molecular y en los péptidos de peso molecular 22, 24 y $26 \mathrm{kDa}$ los cuales también se producen en medio de cultivo. El presente estudio valoró también antígeno metabólico parcialmente purificado mediante una membrana que permite la retención de moléculas de peso mayor a 6-8 kDa, demostrando que cualquiera de los antígenos estudiados puede ser utilizado para discriminar bovinos sanos de infectados mediante la prueba inmunodiagnóstica ELISA.

Los resultados de este estudio no permiten justificar la realización de bloqueos en el ELISA, ya que los valores de absorbancia obtenidos, con y $\sin$ bloqueo, fueron similares. Los tres 
antígenos de F.hepatica -somático (AgS) y metabólicos, excretor-secretor total (AgE/S-T) y excretor-secretor parcialmente purificado (AgE/ S-PP)- debido a su gran capacidad discriminatoria, pueden ser la base para la evaluación del serodiagnóstico de fascioliasis en bovinos en estudios poblacio-nales donde se debe utilizar la presencia del parásito como la prueba de referencia. Durante esta fase, también se deberán establecer los puntos de corte que ofrezcan, dependiendo de las necesidades, la mayor sensibilidad, especificidad o capacidad discriminatoria.

\section{Agradecimientos}

Los autores expresan sus agradecimientos al Instituto Nacional de Salud, entidad que auspició la investigación, a los mataderos municipales de Zipaquirá y Chía y al Frigorífico Guadalupe por permitir la toma de muestras de bovinos llevados a sacrificio, de sangre y la recolección de adultos de $F$. hepatica de los hígados decomisados.

A los médicos veterinarios Gonzalo Luque, Víctor Vera y Everardo Gómez por su colaboración en la recolección de algunas de las muestras de sangre de bovinos que habitaban en zona no endémica de fasciolasis y su orientación en los aspectos veterinarios e inmunológicos de los bovinos.

\section{Referencias}

1. Quiroz HR. Fasciolasis, dicroceliasis y paramfistomosis. En: Noriega, ed. Parasitología y enfermedades parasitarias de animales domésticos. México: Editorial Limusa, 1984:231-59.

2. Ross JG. The economics of Fasciola hepatica infections in cattle. Br Vet J 1970;126:13-5.

3. Botero D, Restrepo M. Parasitosis humanas. 2a ed. Medellín: Corporación para Investigaciones Biológicas (CIB), 1992:299.

4. Peña NE, Parra D. Las enfermedades de los animales en Colombia. Bogotá, D.C.: Instituto Colombiano Agropecuario (ICA), 1980; Documento de trabajo No.20, código 10-6-020-80.

5. Reyes CM, Palacio A. Comparación de la técnica de inmunoensayo en capa delgada respecto a la técnica de Dennis para el diagnóstico de la Fasciola hepatica en bovinos. Tesis de grado. Bogotá, D.C., Colombia: Universidad Nacional de Colombia, 1988:1-114.
6. Hillyer GV. Fasciolasis, paragonimiasis, clonorchiasis, and opisthorchiasis. In: Walls KW, Schantz PM, eds. Immunodiagnosis of parasitic diseases. Vol 1. Helminthic diseases. Boca Raton: Academic Press, Inc., 1986:39-68.

7. Gómez A, Lebrija A. Intradermorreacción. En: Morilla A, Bautista C, eds. Manual de inmunología. México: Diana, 1986:256-8.

8. Arango DC, Cotrino JE. Estudio comparativo entre el serodiagnóstico por la reacción de fijación de complemento y la técnica de Dennis, para el diagnóstico de la distomatosis hepática. Tesis de grado. Bogotá, D.C., Colombia: Universidad Nacional de Colombia, 1986:1-96.

9. Ruiz-Navarrete A. Pruebas de precipitación. En: Morilla A, Bautista C, eds. Manual de inmunología. México: Diana, 1986:52-3.

10. de Morilla AC, Ruiz-Navarrete A. Técnicas de electroforesis. En: Morilla AC, Bautista C, eds. Manual de inmunología. México: Diana, 1986:63-73.

11. Barret JT. Basic immunology and its medical application. 2nd ed. St. Luois: Mosby Company, 1980:165-6.

12. Mar R. Inmunofluorescencia. En: Morilla AC, Bautista C, eds. Manual de inmunología. México: Diana, 1986: 97-104.

13. Burden D, Hammet NC. Microplate enzyme linked immunosorbent assay for antibody to Fasciola hepatica in cattle. Vet Rec 1978;103:158.

14. Pfister K, Daveau CH, Ambroise-Thomas P. Partial purification of somatic and excretory-secretory products of adult Fasciola hepatica and their application for the serodiagnosis of experimental and natural fascioliasis using on ELISA. Res Vet Sci 1984;37:3943.

15. Voller A, Bidwell DE, Bartlett A. Enzyme immunoassays in diagnostic medicine. Theory and practice. Bull WHO 1976;53:55-65.

16. Voller A, Bartlett A, Bidwell DE. Enzyme immunoassays for parasitic diseases. Trans R Soc Trop Med Hyg 1976;70:98-106.

17. Van Tiggele LJ, Over HJ. Serological diagnosis of fascioliasis. Vet Parasitol 1976;1:239-48.

18. Ambroise-Thomas P, Desgeorges PT, Bouttaz M. Le diagnostic immunoenzymologique (ELISA) de la fasciolase humaine et bovine. Detection d'anticorps et/ ou d'antigenes circulants. Ann Soc Belg Med Trop $1980 ; 60: 47-60$

19. Farrell CJ, Shen DT, Wescott RB, Lang BZ. An enzyme-linked immunosorbent assay for diagnosis of Fasciola hepatica infection in cattle. Am J Vet Res 1981;42:237-40.

20. Wescott RB, Farrell CJ, Shen DT. Diagnosis of naturally occuring Fasciola hepatica infections in cattle 
with and enzyme-linked immunosorbent assay. Am $J$ Vet Res 1984;45:178-9.

21. Hillyer GV, Sánchez Z, de-León D. Immunodiagnosis of bovine fascioliasis by enzyme-linked immunosorbent assay and immunoprecipitation methods. J Parasitol 1985;71:449-54.

22. Wyckoff III JH, Bradley RE. An optimized enzymelinked immunosorbent assay for quantitative diagnosis of bovine fascioliasis. J Parasitol 1986;72:439-44.

23. Welch RD, Smith PH, Malone JB, Holmes RA, Geaghan JP. Herd evaluation of Fasciola hepatica infection levels in Louisiana cattle by an enzyme-linked immunosorbent assay. Am J Vet Res 1987;48:345.

24. Sinclair IJ, Wassall DA. Sero-diagnosis of Fasciola hepatica infections in cattle. Vet Parasitol 1988;27: 283-90.

25. Lehner RP, Sewell MMH. A study of the antigen produced by adult Fasciola hepatica maintained in vitro. Paras Immunol 1980;2:99-109.

26. Irving DO, Howell MJ. Characterization of excretorysecretory antigens of Fasciola hepatica. Parasitology 1982;85:179-87.

27. Zimmerman GL, Nelson MJ, Clark CRB. Diagnosis of ovine fascioliasis by a dot enzyme-linked immunosorbent assay: a rapid microdiagnostic technique. Am J Vet Res 1985;46:1513-15.

28. Rivera-Marrero CA, Santiago N, Hillyer GV. Evaluation of immunodiagnostic antigens in the excretorysecretory products of Fasciola hepatica. J Parasitol 1988;74:646-52.

29. Santiago N, Hillyer GV, García-Rosa M, Morales MH. Identification of functional Fasciola hepatica anti- gens in experimental infections in rabbits. Am J Trop Med Hyg 1986;35:135-40.

30. Hillyer GV, Soler-de-Galanes M. Initial feasibility studies of the fast-ELISA for the immunodiagnosis of fascioliasis. J Parasitol 1991;77:362-5.

31. Rodríguez-Pérez J, Hillyer GV. Detection of excretory-secretory circulating antigens in sheep infected with Fasciola hepatica and with Schistosoma mansoni and F. hepatica. Vet Parasitol 1995;56:57-66.

32. Nierenberg AA, Feinstein AR. How to evaluate a diagnostic marker test. Lessons from the rise and fall of dexamethasone suppression test. JAMA 1988;259: 1699-1702.

33. Lowry OH, Rosebrough NI, Farr AL, Randall RJ. Protein measurement with the folin-phenol reagent. $J$ Biol Chem 1951;193:265-75.

34. Espino AM, Duménigo DE, Fernández R, Finlay CM. Immunodiagnosis of human fasciolasis by enzyme-linked immunosorbent assay using excretorysecretory products. Am J Trop Med Hyg 1987;37:6058.

35. de Savigny DH. In vitro maintenance of Toxocara canis larvae and a simple method for the production of Toxocara ES antigen for use in serodiagnostic tests for visceral larva migrans. J Parasitol 1975;61:781-2.

36. Beck JR, Shultz EK. The use of relative operating characteristic (ROC) curves in test performance evaluation. Arch Pathol Lab Med 1986;110:13-20.

37. Kurstak E. Progress in enzyme immunoassays: production of reagents, experimental design and interpretation. Bull WHO 1985;63:793-811. 